\title{
Effect of coronary artery bypass surgery on ventricular functions in patients with poor left ventricular function
}

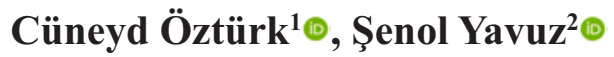 \\ ${ }^{1}$ Department of Cardiovascular Surgery, Kadıköy Florence Nightingale Hospital, İstanbul, Turkey \\ ${ }^{2}$ Department of Cardiovascular Surgery, University of Health Sciences, Bursa Yüksek Ihtisas Training and Research Hospital, Bursa, \\ Turkey
}

DOI: $10.18621 /$ eurj.519917

\begin{abstract}
Objectives: The aim of the present study was to compare preoperative / postoperative ventricular functions of patients with ventricular dysfunction who were planned for coronary artery bypass grafting (CABG) using echocardiography and angiography, and to evaluate whether there was a significant improvement in ventricular function.

Methods: This prospective study included 30 patients with poor ventricular function who had undergone CABG at the Cardiovascular Surgery Clinics of Bursa Yüksek Ihtisas Hospital. The patients' ventricular functions were compared preoperatively and postoperatively at the $2^{\text {nd }}, 6^{\text {th }}$ and $12^{\text {th }}$ months.

Results: Of the patients, 28 were males, and the mean age was $60.1 \pm 8$ years (range 39-71). In these cases, functional capacity improved within the early postoperative period, and global ventricular functions improved within the postoperative first year. The improvement in ejection fraction results was statistically significant at 6 months and 12 months $(p<0.05)$. A significant decrease was observed in left ventricular enddiastolic pressures within one year $(p<0.001)$. For the performance score, improvement was significant from the 2 nd month $(p<0.05)$.

Conclusions: Our findings show that CABG improves ventricular function in terms of EF, PS, LVEDP and NYHA classification. In conclusion, we consider that CABG is a significantly effective option in patients with poor ventricular function.
\end{abstract}

Keywords: Coronary artery bypass grafting, poor left ventricular function, ischemic heart disease

Received: January 31, 2019; Accepted: February 28, 2019; Published Online: March 11, 2019

I schemic heart disease is caused by insufficient transport of oxygenated blood in myocardium. The regional distribution of highly constricted and occluded lesions results in myocardial ischemia or infarction. Therefore, myocardial function abnormalities are generally segmental or regional in patients with ischemic heart disease. When very common myocardial damage occurs due to high degree of stenosis and ob- struction in many places of the coronary arteries, the entire left ventricle may show reduced contraction strength. In acute coronary occlusion, there is systolic curvature or dyskinesia at the center of the relevant region, hypokinesia- or akinesia-induced contraction in the adjacent region, and compensatory hyperfunction in the intact myocardium. 80\% decrease in blood flow causes akinesia, and 95\% decrease in dyskinesia. If 
the affected myocardium is small, the regional left ventricular dysfunction is balanced by the hyperfunction of the intact region, and the global left ventricular function is preserved $[1,2]$. Each abnormality of the affected ventricular wall motion as a result of disruption of blood flow creates an additional burden for each ventricle. This dysfunction of the heart may be major and minor changes depending on the condition of the vessel occlusion and the extent of the affected area. The best method for the diagnosis of vascular occlusion is selective coronary arteriography. After the occlusion, left ventricle and its function are the most important region and function affected [1-3].

Knowing left ventricular performance in ischemic heart disease is of great importance for the management of the treatment. To assess left ventricular performance, the extent and severity of regional contraction abnormalities should be determined. For this purpose, end diastolic volume (EDV) after heart contraction, blood volume (stroke volume $[\mathrm{SV}]$ ) and residual volume at end of systole (End-sistolic volume [ESV]) are important information about this subject. Ejection fraction (EF) reflects left ventricular pump function [1-4]. The results of these measurements show the performance of left ventricle, and the effectiveness of the treatment is followed according to these results. Coronary artery surgery studies so far have shown that patients with severe left ventricular dysfunction benefit from coronary revascularization [3, 4]. Some studies reported failure in regional wall movements after treatment, and these evaluations led to questions in clinicians' minds [4-7].

The aim of the present study was to compare preoperative/postoperative ventricular functions of in patients with ventricular dysfunction who were planned for coronary artery bypass grafting (CABG) using echocardiography and angiography, and to evaluate whether there was a significant improvement in ventricular function.

\section{METHODS}

\section{Selection of patients}

Thirty patients with coronary artery disease who were considered to have poor ventricular function were enrolled in the study at the Cardiovascular
Surgery Department of Bursa Yüksek Ihtisas Training and Research Hospital. EF, left ventricular enddiastolic pressures (LVEDP), functional capacities (FC) and performance scores (PS) were used as criteria. CABG was performed on the patients with severe left ventricular failure who were met with these criteria and who had coronary artery disease.

\section{Evaluation}

Preoperative and postoperative ventricular function results of the patients were compared. In ventricular function was evaluated as poor using; (i) $\mathrm{EF}<35 \%$, preoperative and postoperative LVEDP, Mmode, 2D echocardiography were measured, (ii) LVEDP $>20 \mathrm{mmHg}$ criteria were determined, and LVEDP was measured preoperatively and postoperatively at 12th months, and (iii) Performance score $>15$ was accepted. Performance score is not a criterion alone, but it is meaningful when the analysis of each segment is performed together with other criteria. Although widespread hypokinesia is a low performance score, it is clinically poor in terms of ventricular function. The ventricular aneurysm in the two segments shows a high performance score, but has a better ventricular function than the common hypokinesia.

The performance score was calculated as 1-6 points by dividing the heart into seven segments. The total score of seven segments was added after each score was calculated for each segment. According to these points, the subjects included in this study had moderate and severe dysfunctional ventricular functions. Functional capacities of the patients were evaluated preoperatively and postoperatively according to the New York Heart Association (NYHA) criteria $[1-3,7]$. In addition, risk factors of patients, previous myocardial infarction, type of angina, cardiothoracic index, vascular lesions, echocardiography and wall movements of angiography, postop used inotrope, pacemaker, IABA, the drugs they used were questioned.

The patients' morbidity and mortality rates were determined. Operative death was defined as death at the postoperative 30th day or at the time of hospitalization. The new Q-wave or CK-MB elevation of perioperative MI was defined by the fact that $\mathrm{MB}$ isoenzyme was greater than $50 \mathrm{U} / \mathrm{L}$ or greater than $8 \%$ 
of total CK. Preoperative and postoperative ECGs were evaluated. A preoperative intraaortic balloon pump (IABP) was placed in unstable angina that did not respond to medical therapy or unstable angina with ventricular dysfunction or ECG changes in the operating room. Low-output syndrome was diagnosed in cases where IABP was needed to increase circulating system, or when inotropic medication was needed to keep cardiac index greater than $2 \mathrm{~L} / \mathrm{min}$. Preoperative balloons were diagnosed with low-output when postoperative inotropic treatment was required.

\section{Coronary revascularization}

Mild hypothermia $\left(34^{\circ} \mathrm{C}\right)$ and membrane oxygenator were used in all patients undergoing CABG. In all cases, distal anostomosis between the native coronary artery and the graft was performed under the cross-clamp, and the heart was stopped using blood cardioplegia at the room temparature, and under proximal anostomosis under the cross-clamp. Blood cardioplegia was given regularly in 20 minutes. A total of 1-5 coronary bypass grafts were applied to the cases. Preoperative angina and heart failure symptoms were evaluated according to NYHA classification. All living cases were checked at the 2nd, 6th and 12th months. Echocardiography was performed preoperatively. LVEDP was measured, and after approximately 12 months, all these patients were repeated.

\section{Statistical Analysis}

Statistical analysis was made using the SPSS version 25.0 software (SPSS IBM, Chicago, IL, USA). Descriptive statistics was given as a mean \pm standard deviation for continuous variables, and the normality test of the numerical variables was checked by Kolmogorov Smirnov test. Independent Samples t test was used in the comparison of two independent groups. Categorical variables werre given as number and percentage. Preoperative values and postoperative results were evaluated using Paired Samples t test. $p$ $<0.05$ was considered statistically significant.

\section{RESULTS}

Of the patients, 28 were males, and two were females. The mean age was $60.1 \pm 8$ years (range 39-
71 years). All patients had angina pectoris (Grade III and IV according to the NYHA). Thirty patients had myocardial infarction (MI) at least once. A total of 22 patients had congestive heart failure (CHF) consisted of dyspnea, orthopnea, and clinical and radiological findings of pulmonary congestion. These patients were under digital+diuretic therapy. The preoperative clinical findings of the patients are summarized in Table 1.

Mean EF values of patients who underwent coronary bypass surgery were insignificant in the second month $(p=0.718)$. However, the improvement in mean EF results was statistically significant at 6 months and 12 months $(p=0.011$ and $p=0.004$, respectively) (Table 2). Mean LVEDP values were significantly decreased in coronary bypass patients in one year $(p<0.001)$ (Table 3$)$. The improvement of mean performance scores (PS) for coronary bypass patients after the $2^{\text {nd }}$ month was statistically significant ( $p=0.012, p=0.007$ and $p<0.001$, respectively for each measurement period) (Table 4). In patients with coronary bypasses, improvement was also statistically significant after 2 months according to the mean NYHA Classification $(p<0.001$ for each measurement period) (Table 5).

Table 1. Preoperative clinical findings of the patients

\begin{tabular}{lc}
\hline Baseline characteristics & Data $(\mathbf{n}=\mathbf{3 0})$ \\
\hline $\begin{array}{l}\text { Age (years) } \\
\text { range }\end{array}$ & $60.1 \pm 8$ \\
Gender, male & $39-71$ \\
Chest CTI & $28(94 \%)$ \\
$\quad$ Increased & \\
$\quad$ Borderline & $18(60 \%)$ \\
MI history & $12(40 \%)$ \\
$\quad$ Anteroseptal & $15(50 \%)$ \\
$\quad$ Inferior & $15(50 \%)$ \\
Hipertension & $17(56.6 \%)$ \\
Diabetes Mellitus & $3(10 \%)$ \\
Smoking & $22(73 \%)$ \\
Heredity & $5(16.6 \%)$ \\
High cholestherol & $10(33.3 \%)$ \\
\hline
\end{tabular}

$\mathrm{CTI}=$ cardio-thoracic index, $\mathrm{MI}=$ myocard infarction 
Table 2. Distribution of preoperative and postoperative ejection fraction values

\begin{tabular}{lcccc}
\hline EF values (\%) & Preoperative (n) & $\begin{array}{c}\text { Postoperative 2 }^{\text {nd }} \\
\text { month (n) }\end{array}$ & $\begin{array}{c}\text { Postoperative 6 }^{\text {th }} \\
\text { month (n) }\end{array}$ & $\begin{array}{c}\text { Postoperative 12 }^{\text {th }} \\
\text { month (n) }\end{array}$ \\
\hline$>\mathbf{3 5}$ & 0 & 0 & 3 & 9 \\
$\mathbf{3 1 - 3 5}$ & 16 & 2 & 17 & 12 \\
$\mathbf{2 6 - 3 0}$ & 9 & 11 & 6 & 8 \\
$\mathbf{2 1 - 2 5}$ & 4 & 5 & 4 & 8 \\
$<\mathbf{2 1}$ & 1 & 3 & 0 & 0 \\
Mean EF & 29.233 & 28.56 & 31.6 & 33.8 \\
$\boldsymbol{p}$ value (between & - & 0.718 & $\mathbf{0 . 0 1 1}$ & $\mathbf{0 . 0 0 2}$ \\
mean EFs)* & - & &
\end{tabular}

$\mathrm{EF}=$ ejection fraction. ${ }^{*} p$ values were calculated in comparison to the preoperative mean EF values.

\section{Coronary revascularization}

One $(3.3 \%)$ of the cases had one, four $(13.3 \%)$ had bilateral, 12 had (40\%) triplet, nine (30\%) had four, four $(13.3 \%)$ had five, and 21 patients $(70 \%)$ had internal mammary artery used for the operation. The time of the aortic cross-clamp and the time of cardiopulmonary bypass were $61 \pm 19 \mathrm{~min}$ and $97 \pm$ 27 min, respectively. The mean extubation time was 3.4 days. Average days of stay in intensive care unit are 5.6 days; the mean hospital stay was 15.8 days.

Table 3. Distribution of preoperative and postoperative left ventricle enddiastolic pressure values.

\begin{tabular}{lccc}
\hline LVEDP (mmHg) & Preoperative (n) & Postoperative $\mathbf{1 2}^{\text {th }}$ month (n) & $p$ value \\
\hline $\mathbf{3 1 - 3 5}$ & 4 & 4 & - \\
$\mathbf{2 6 - 3 0}$ & 18 & 2 & - \\
$\mathbf{2 0 - 2 5}$ & 8 & 24 & - \\
Mean LVEDP & 27.966 & 21.9 & $<\mathbf{0 . 0 0 1}$ \\
\hline
\end{tabular}

LVEDP $=$ left ventricle enddiastolic pressure

\section{Surgical complications}

The operative mortality was $9 \%$. These cases were excluded from the study. Five patients (16.6\%) underwent IABP due to perioperative low cardiac output. Femoral embolectomy was performed in 4 $(10.3 \%)$ patients with IABP. Five patients $(16.6 \%)$ had peroperative $Q$ wave myocardial infarction detected by postoperative ECG.

Table 4. Distribution of preoperative and postoperative performance scores

\begin{tabular}{lcccc}
\hline PS values (points) & Preoperative (n) & $\begin{array}{c}\text { Postoperative } \\
\mathbf{2}^{\text {nd }} \text { month (n) }\end{array}$ & $\begin{array}{c}\text { Postoperative 6 } \\
\text { month (n) }\end{array}$ & $\begin{array}{c}\text { Postoperative } \\
\mathbf{1 2}^{\text {th }} \text { month (n) }\end{array}$ \\
\hline$<\mathbf{1 5}$ & 0 & 4 & 5 & 5 \\
$\mathbf{1 5 - 2 0}$ & 17 & 21 & 23 & 21 \\
$\mathbf{2 1 - 2 5}$ & 12 & 5 & 2 & 1 \\
$\mathbf{2 6 - 3 0}$ & 1 & 0 & 0 & 0 \\
$\begin{array}{l}\text { Mean PS } \\
\boldsymbol{p} \text { value (between } \\
\text { mean PS values)* }\end{array}$ & 19.76 & 18.7 & 17.26 & 6.83 \\
\hline
\end{tabular}

PS $=$ performance scoring. ${ }^{*} p$ values were calculated in comparison to the preoperative mean PS values. 
Table 5. Distribution of preoperative and postoperative functional capacity according to NYHA Classification

\begin{tabular}{|c|c|c|c|c|}
\hline & Preoperative (n) & $\begin{array}{l}\text { Postoperative } \\
2^{\text {nd }} \text { month (n) }\end{array}$ & $\begin{array}{c}\text { Postoperative } 6^{\text {th }} \\
\text { month (n) }\end{array}$ & $\begin{array}{l}\text { Postoperative } \\
12^{\text {th }} \text { month (n) }\end{array}$ \\
\hline NYHA Class I & 0 & 0 & 0 & 0 \\
\hline NYHA Class II & 3 & 10 & 12 & 13 \\
\hline NYHA Class III & 19 & 14 & 13 & 13 \\
\hline NYHA Class IV & 8 & 6 & 5 & 4 \\
\hline Mean & 3.23 & 2.86 & 2.76 & 2.7 \\
\hline $\begin{array}{l}p \text { value (between mean } \\
\text { NYHA values)* }\end{array}$ & - & $<0.001$ & $<0.001$ & $<0.001$ \\
\hline
\end{tabular}

NYHA $=$ New York Heart Association. ${ }^{*} p$ values were calculated in comparison to the preoperative mean NYHA values.

\section{DISCUSSION}

Coronary artery surgery is the most effective and common method of left ventricular performance. This surgical method has been applied to the patients in the high risk group safely. Mortality after coronary artery surgery of about $3 \%$ before 70 s decreased to $0.4-0.5 \%$ in the early $80 \mathrm{~s}$ [3]. Coronary artery surgery studies so far have shown that patients with severe left ventricular dysfunction benefit from coronary revascularization [4]. Some studies reported failure in regional wall movements after treatment, and these evaluations led to questions in clinicians' minds. Correction of left ventricular functions, one of the most important factors for the survival of a patient with coronary artery disease, is one of the aims of CABG [5-8]. To date, contradictory studies on the left ventricular function of CABG have been published. Some studies reported failure in the regional wall movements after surgery, while others reported improvement in the dysfunction zone with or without total ventricular performance improvement [4-7].

Patients with $\mathrm{CABG}$ have a higher mortality rate in patients with severe left ventricular failure compared to those with normal left ventricular function. This rate has been reported to vary from 5\% to $80 \%$ [9-11]. Hung et al. [9] reported that the operative mortality rate was $12 \%$ in their studies. This rate is $1-2 \%$ in patients with normal LV function. In these series, the identification of LV failure was emphasized as radiological cardiomegaly, ejection fraction was $<0.35$, and the majority of patients were emphasized as congestive heart failure. Some studies have included aneurysmectomy cases [10] while some studies reported the results have changed from weak to good [3-7]. Our study included 30 living patients with preoperative severe left ventricular failure. Preoperative and postoperative clinical status of the patients and objective evaluations of left ventricular functions were compared.

Researchers report different types of poor ventricular function defines with improved operation results. Inamdar et al. [12] evaluated $\mathrm{EF}<40 \%$ as poor ventricular function. CASS defines EF as $<36 \%$ [13]. According to Makkar et al. [14] EF was $<20 \%$. In their three-year study, Kron et al. [15] reported a three-year survival rate of $83 \%$ after coronary revascularization in ischemic cardiomyopathy patients with $20 \%$ of $\mathrm{EF}$, and reported that myocardial revascularization should be tested for patients with severe ischemic cardiomyopathy prior to transplantation. Louie et al. [16] reported a three-year survival rate as $72 \pm 10 \%$ for patients undergoing revascularization or transplantation as a result of ischemic cardiomyopathy, and as $73 \pm 6 \%$ for the transplantation-patients. In the same report; preoperative EFs were $26 \pm 9 \%$, left ventricular end diastolic dimension (LVEDD) was $68 \pm 3 \mathrm{~mm}$, and NYHA class was $3.9 \pm 0.4$ preoperatively. LVEDP was reported to be as $36 \pm 9 \%$, LVEDD was $64 \pm 6 \mathrm{~mm}$, and NYHA class was $1.2 \pm 0.4$ compared to postoperative values. As a result, they stated that successful coronary revascularization could be performed with coronary artery and operative 
mortality was acceptable in the patients with (i) LVEDD $<70 \mathrm{~mm}$, (ii) coronaries appropriate for bypass, and (iii) reversible myocardial ischemia in PET [16].

Because left ventricle bilateral performance could be changed significantly within the postoperative first year, Mintz et al. [17] summarized their findings as; (i) not to use wide-interval evaluations in determining the operation results in the same category, (ii) studies conducted at postoperative 2 nd months or after could not take the early postoperative period with rapid changes as the subject, (iii) left ventricular performance with frequent sequential studies to evaluate the results of a single patient, and (iv) the wall movements in the previous infarct areas could be improved with CABG. The mechanism of low enddiastolic volume observed in the early postoperative period is the diastolic filling time, which is reduced by tachycardia after CABG. Since the pericardium is wide open during surgery, it is normal for the end-diastolic volume not to be affected as no reposition is performed. The change in left ventricular compliance (due to intra-opioid) seems to not limit the end-diastolic volume because these changes are resolved within postoperative 24 hours, and our earliest study was not within this time [17]. Operative mortality $(9 \%)$ is a generally acceptable mortality in patients with poor ventricular disease according to the criteria we used. In order to reduce the need for $\mathrm{O} 2$, ischemic myocardium slows down segmental wall movements, leading to hemodynamic changes starting from elevation in LVEDP. This results as the clinical symptoms. However, it is thought that vascular tissue can function normally by revascularizing the segment, and hence the clinical manifestation may improve.

Almost all of alternative treatment methods in extremely limited ventricle (cardiac transplantation, asist device methods, cardiomyoplasty, etc.) have certain morbidity and mortality. The cost effect ratio of these methods should be discussed. Because the costs are quite high. In the countries with donor problems similar to Turkey, CABG may still be considered the most radical solution in the severe ventricular group. In our study group, preoperative ventricular functions were compared with the postoperative period. Therefore, the study was carried out in the living patients.
Among the methods of revascularization, the method called beating heart and the use of minithoracotomy methods without the need for sternotomy in recent years, especially the bad effects of the cardiopulmonary bypass on poor ventricular function is possible in selected cases. Long-term outcomes in patients with severe ventricular dysfunction are better in surgery than in medical treatment. Operative mortality rate varies between $1.6-50 \%$ in high-risk patients. This ratio should be kept as low as possible [18]. Louie et al. [16] concluded that successful coronary revascularization could be performed for patients with coronary artery bypass grafting and LVEDP $<70$ and reversible myocardial ischemia on PET and operative mortality was acceptable. In our study, the first improvement in early postoperative period (within the first 2 months) was seen in functional capacity (FC) (according to the NYHA) and angina classification (Canadian). Although there is no revascularized myocardial ischemic pain, there is no global improvement in ventricular function in the early period, and the exercise capacity is improved. At the postoperative $2^{\text {nd }}$ month, EF decreased below the preoperative value, but increased to preoperative value at 6 months. Performance score (PS) starts to improve since the postoperative $2^{\text {nd }}$ month. The cleavage of the ischemic region also starts to improve in segmental movements, but it affects the EF globally in 6 months. The postoperative course of the patients in terms of both clinical and ventricular functions can reach at the best condition in 6-12 months. However, in LVEDP (30 $\mathrm{mmHg}$ ) cases, LVEDP has not decreased despite the clinical improvement. This is probably due to the low stay of stiff tissue-induced ventricular compliance secondary to ischemia.

In our study, two patients with LVEDPs of 30 $\mathrm{mmHg}$ and $35 \mathrm{mmHg}$ and EFs of $24 \%$ and $26 \%$ were operated urgently due to acute pulmonary edema and cardiogenic shock. Both of these cases had 2nd- and 6th-month echocardiographic measurements as LVEDPs of $50 \mathrm{mmHg}$ and $50 \% \mathrm{mmHg}$ and EFs of $45 \%$ and $46 \%$. If there is angina in patients with severe $\mathrm{LV}$ failure, the operation relieves the angina and provides long-term survival. If $\mathrm{CHF}$ is a major symptom, CABG disappoints the results [9]. In our study, there was no improvement in the very high LVEDP group at the postoperative 12th month. We 
used blood cardioplegia in all of our cases, we underwent proximal anostomosis under the crossclamp, and thought to minimize reperfusion injury. We tried to emphasize the importance of myocardial protection and surgical procedure in extremely limited ventricles.

Christakis et al. [18] reported that myocardial protection type has a role on operative mortality in patients with EF of $<20-40 \%$, and that they had better results in high-risk cases when they switched from crystalloid to blood cardioplegia. In recent years, they used warm induction as warm terminal cardioplegic infusion, and they reported that they had positive results with a continuous warm antegrade or combination of antegrade and retrograde. In patients with severe LV insufficiency with CAD, CABG can be applied because of the reduction of angina and long-term survival in patients [18]. Concerning the effects of myocardial revascularization in diffuse LV insufficiency, Mundth et al. [10] have reported improved LV contractions in 4 of 5 patients reevaluated with LV angiography. Kloner et al. [19] observed an increase in ejection fraction in some patients, but they did not specify a number. In our study, there was no change in EDV in patients with open and closed grafts. Some studies found no change in postoperative EDV. However, some studies found a decrease and increased in postoperative EDV in EFdepressed patients found decreased postoperative EDV in completely revascularized patients [18-21]. Christakis et al. [18] reported that patients with severe ventricular dysfunction who had isolated CABG were at high risk, and their risk was due to the urgency of the operation. They emphasized that efforts to improve outcomes should be intensified in patient selection, in the development of myocardial protection, and in the treatment of preoperative less aggressive myocardial ischemia. They also demonstrated EF, the urgency, reoperation, advanced age, left main coronary artery stenosis, and use of crystalloid cardioplegia as the factors for increasing operative mortality in patients with EF of $<20 \%$ [16]. In the group called poor ventricle, inotropic use, IABP usage, duration of mechanical ventilation support, duration of intubation, duration of stay in hospital and longer hospital stay are longer than in the group with good ventricular ischemic group. Complications related to IABP and infection complications were more frequent.

\section{Limitations}

There are some limiting aspects of our work. The study has the disadvantages of being retrospective and uncontrolled and thus produces an uncertain hypothesis. Since echocardiograms are not routinely taken after CABG surgery, selection may be a mistake. Echocardiographic measurements were performed only three times in individual patients, so we cannot say whether these changes show consistency in the long term. In addition, echocardiography is not the best way to evaluate cardiac measurement, the observed variability in EF measurement between observers is $6 \%$ [21]. The study is a thesis study based on observations of cases. Case differences may vary according to time, location and region.

\section{CONCLUSION}

In conclusion, $\mathrm{CABG}$ can be performed with an acceptable mortality and morbidity in patients with ischemia-induced poor ventricular function. In these cases, preoperative functional capacity and global ventricular function improved. While functional capacity is improved in the early postoperative period, recovery of global ventricular functions is in the process of postoperative 1 st year. In patients with a LVEDP of more than $30 \mathrm{mmHg}$, FC (NYHA) is recovering, whereas global ventricular function does not show a significant change. However, even in these cases the quality of life is significantly increased. CABG is considered as the first choice in this group of patients that modern surgery techniques, cardiopulmonary bypass and transplantation under intensive care conditions are discussed, especially in our country.

\section{Conflict of interest}

The authors disclosed no conflict of interest during the preparation or publication of this manuscript.

\section{Financing}

The author disclosed that they did not receive any grant during conduction or writing of this study.

\section{REFERENCES}

[1] Ahmadi A, Stone GW, Leipsic J, Shaw LJ, Villines TC, Kern 
MJ, et al. Prognostic determinants of coronary atherosclerosis in stable ischemic heart disease: anatomy, physiology, or morphology? Circ Res 2016;119:317-29.

[2] Denktas AE, Paniagua D, Jneid H. Coronary physiology assessment for the diagnosis and treatment of stable ischemic heart disease. Curr Atheroscler Rep 2016;18:62.

[3] Koene RJ, Kealhofer JV, Adabag S, Vakil K, Florea VG. Effect of coronary artery bypass graft surgery on left ventricular systolic function. J Thorac Dis 2017;9:262-70.

[4] Yancy CW, Jessup M, Bozkurt B, Butler J, Casey DE Jr, Drazner MH, et al; American College of Cardiology Foundation; American Heart Association Task Force on Practice Guidelines. 2013 ACCF/AHA guideline for the management of heart failure: a report of the American College of Cardiology Foundation/American Heart Association Task Force on Practice Guidelines. J Am Coll Cardiol 2013;62:e147-239.

[5] Kim MS, Lee JH, Cho HJ, Cho JY, Choi JO, Hwang KK, et al. KSHF Guidelines for the Management of Acute Heart Failure: Part III. Specific management of acute heart failure according to the etiology and co-morbidity. Korean Circ J 2019;49:46-68.

[6] Velazquez EJ, Bonow RO. Revascularization in severe left ventricular dysfunction. J Am Coll Cardiol 2015:17;65:615-24. [7] Nizamic T, Murad MH, Allen LA, McIlvennan CK, Wordingham SE, Matlock DD, et al. Ambulatory inotrope infusions in advanced heart failure: a systematic review and meta-analysis. JACC Heart Fail 2018;6:757-67.

[8] Sobolev BG, Fradet G, Hayden R, Kuramoto L, Levy AR, Fitzgerald MJ. Survival benefit of coronary-artery bypass grafting accounted for deaths in those who remained untreated. J Cardiothorac Surg 2008;3:47.

[9] Hung J, Kelly DT, Baird DK, Hendel PN, Leckie BD, Grant $\mathrm{AF}$, et al. Aorta-coronary bypass grafting in patients with severe left ventricular dysfunction. J Thorac Cardiovasc Surg 1980;79:718-23.

[10] Mundth ED, Harthorne JW, Buckley MJ, Dinsmore R, Austen WG: Direct coronary arterial revascularization. Treatment of cardiac failure associated with coronary artery disease. Arch Surg 1971;103:529-34.

[11] Pepper J. Managing heart failure patients with multivessel disease--Coronary Artery Bypass Graft versus Percutaneous Coronary Intervention. Card Fail Rev 2015;1:118-22.

[12] Inamdar AA, Inamdar AC. Heart failure: diagnosis, management and utilization. J Clin Med 2016;5:62.

[13] Zipes DP, Libby P, Bonow RO, Mann DL, Tomaselli GF. Braunwald's Heart Disease E-Book: A Textbook of Cardiovascular Medicine. International edition, 11th ed, Elsevier, 2018.

[14] Makkar RR, Smith RR, Cheng K, Malliaras K, Thomson LE, Berman D, et al. Intracoronary cardiosphere-derived cells for heart regeneration after myocardial infarction (CADUCEUS): A prospective, randomised phase 1 trial. Lancet 2012;379:895-904. [15] Kron IL, Flanagan TL, Blackbourne LH, Schroeder RA, Nolan SP. Coronary revascularization rather than cardiac transplantation for chronic ischemic cardiomyopathy. Ann Surg 1989;210:348-54.

[16] Louie HW, Laks H, Milgalter E, Drinkwater DC Jr, Hamilton MA, Brunken RC, et al. Ischemic cardiomyopathy. Criteria for coronary revascularization and cardiac transplantation. Circulation 1991;84:290-5.

[17] Mintz LJ, Ingels NB, Daughters GT, Stinson EB, Alderman EL. Sequential studies of left ventricular function and wall motion after coronary arterial bypass surgery. Am J Cardiol 1980,45:210-6.

[18] Christakis GT, Weisel RD, Fremes SE, Ivanov J, David TE, Goldman BS, et al. Coronary artery bypass grafting in patients with poor ventricular function. Cardiovascular Surgeons of the University of Toronto. J Thorac Cardiovasc Surg 1992;103:108392.

[19] Kloner RA, Przyklenk K, Kay GL. Clinical evidence for stunned myocardium after coronary artery bypass surgery. J Card Surg 1994;9:397-402.

[20] Hillis LD, Smith PK, Anderson JL, Bittl JA, Bridges CR, Byrne JG, et al. 2011 ACCF/AHA Guideline for Coronary Artery Bypass Graft Surgery: executive summary: a report of the American College of Cardiology Foundation/American Heart Association Task Force on Practice Guidelines. Circulation 2011;124:2610-42.

[21] Levine GN, Bates ER, Blankenship JC, Bailey SR, Bittl JA, Cercek B, et al. ACCF/AHA/SCAI Guideline for Percutaneous Coronary Intervention: executive summary: a report of the American College of Cardiology Foundation/American Heart Association Task Force on Practice Guidelines and the Society for Cardiovascular Angiography and Interventions. Circulation 2011;124:2574-609. 